\title{
Activity of $\mathrm{B}(\mathrm{OEt})_{3}$-MCM-41 catalyst in the MPV reduction of crotonaldehyde
}

\author{
BURCU UYSAL \\ Department of Chemistry, Akdeniz University, 07058 Antalya, Turkey \\ e-mail: buysal@akdeniz.edu.tr
}

MS received 13 May 2013; revised 10 September 2013; accepted 11 September 2013

\begin{abstract}
Mesoporous silica material MCM-41 was functionalized with boron tri-ethoxide $\left(\mathrm{B}(\mathrm{OEt})_{3}\right)$ groups by the grafting method and denoted as ' $\mathrm{B}(\mathrm{OEt})_{3}-\mathrm{MCM}-41$ '. With the use of TEM, X-ray diffraction, highresolution thermogravimetry (TGA) and $\mathrm{N}_{2}$ adsorption-desorption isotherms, it was shown that the initial hexagonal structure, the high specific surface area, and porosity are retained in the functionalized material. ${ }^{29} \mathrm{Si}$ NMR- and ${ }^{11}$ B NMR- spectroscopies revealed that the surface of MCM-41 consists of boron alkoxide species. The Meerwein-Ponndorf-Verley (MPV) reduction of crotonaldehyde to but-2-en-1-ol was conducted in the presence of $\mathrm{B}(\mathrm{OEt})_{3}-\mathrm{MCM}-41$ catalyst. MPV reduction of crotonaldehyde also showed that functionalization leads to the creation of Lewis acidic sites. A combination of mesoporous structure with Lewis acidic properties makes the MCM-41 functionalized with boron tri-ethoxide groups, useful as solid Lewis acid catalysts.
\end{abstract}

Keywords. MCM-41; $\mathrm{B}(\mathrm{OEt})_{3}$-MCM-41; boron tri-ethoxide; Meerwein-Ponndorf-Verley reduction; chemoselective crotonaldehyde reduction.

\section{Introduction}

MCM-41, and other ordered silica-based molecular sieve materials, have an organized structure, determined by the orientation of the extended pores: high surface area and narrow pore size distribution. ${ }^{1}$ Purely siliceous materials have poor catalytic activity, if any. There have been continuous efforts to confer to these materials catalytic activity by introduction of active sites. Thus, inclusion of $\mathrm{Al}^{3+}$ ions usually results in an increase in the acidity of the materials, making it similar to that of acidic zeolites. ${ }^{2}$ Titanium (IV) ions in siliceous materials can provide active oxidation and photooxidation catalysts. ${ }^{3}$ Introduction of $\mathrm{Ti}^{4+}$ can be achieved either by their incorporation into the siliceous framework or functionalization of the surface.

Functionalization of the MCM-41 surface with metal alkoxides can be regarded as an optional method for the creation of active Lewis acid sites. Functionalization of the MCM-41 surface with metal alkoxides is usually achieved by grafting methods. Several 'MeerweinPonndorf-Verley (MPV)' reduction catalysts such as Al-alkoxides, B-alkoxides, Zr-alkoxides as well as Hf and $\mathrm{Zr}$ alkyl complexes have been anchored on MCM41 or on amorphous $\mathrm{SiO}_{2}$ in order to generate potential catalytic activity. ${ }^{4-9}$ Thus, grafting of MCM-41materials with MPV reduction catalysts yields active Lewis acid sites on MCM-41 materials. ${ }^{4,5,10}$
Reduction of carbonyl compounds by hydrogen transfer from an alcohol is known as the 'MeerweinPonndorf-Verley reaction' or 'MPV reaction' in organic chemistry and can be performed under mild conditions using Lewis acids as catalyst. ${ }^{11,12}$ The MPV reduction of carbonyl compounds is a highly selective reaction since only the carbonyl group coordinates with the Lewis acid centre, while the double bond remains unreacted. ${ }^{13}$ Therefore, the MPV reduction offers a facile access to unsaturated alcohols, many of which are important starting materials for the production of fine chemicals. ${ }^{14}$ Traditionally, the MPV reaction can be catalysed using homogeneous catalysts such as metal alkoxides. Heterogeneous catalysts for the MPV reactions include zeolites, ${ }^{15-17}$ grafted alkoxides, ${ }^{8,18}$ metal oxides such as magnesium oxide, zirconia, silica, alumina, ${ }^{19}$ etc. A major advantage of heterogeneous catalysis over homogeneously catalysed MPV reactions is that the catalysts can easily be separated from the liquid reaction mixture. ${ }^{7,15}$

In the literature, boron (B) has been incorporated into the catalyst structure in order to generate potential catalytic activity. ${ }^{20-22}$ There are different studies which used B-modified MCM-41 for catalyst systems. Jiamwijitkul and coworkers investigated the effect of B-modification on the MCM-41-supported dMMAO/zirconocene catalyst during ethylene/1-octene copolymerization. ${ }^{23}$ Also, catalytic performance of Al,B-MCM-41 materials for 
the cyclohexanone oxime rearrangement was studied by Conesa and coworkers. ${ }^{24}$ MCM-41 mesoporous materials $[\mathrm{Si} /(\mathrm{Al}+\mathrm{B})$ molar ratio of 20$]$, with $\mathrm{Al} / \mathrm{B}$ ratio in the range of 2-0.5, were prepared by direct synthesis using tetraethyl orthosilicate (TEOS), boric acid $\left(\mathrm{H}_{3} \mathrm{BO}_{3}\right)$ and $\mathrm{Cl}_{3} \mathrm{Al} .6 \mathrm{H}_{2} \mathrm{O}$ as silica, boron and aluminum sources, respectively, and cetyltrimethylammonium bromide $(\mathrm{CTABr})$ as the template, following the procedure described by Grün et al. ${ }^{25}$ with some variations.

In the present article, we demonstrate how functionalization via grafting with boron tri-ethoxide groups influences the structural characteristics and produces Lewis acidic sites on MCM-41 material. In the previous study, we used this procedure to functionalize MCM-41 with boron tri-isopropoxide groups in order to develop new solid Lewis acid catalyst ' $\mathrm{B}\left(\mathrm{O}^{i} \mathrm{Pr}\right)_{3}-\mathrm{MCM}-41^{\prime}$. The results were found encouraging for reduction of a variety of $\alpha, \beta$-unsaturated aldehydes and ketones. ${ }^{4,10} \mathrm{Up}$ to the present time, there has not been any literature report the preparation of boron tri-ethoxide grafted MCM-41 catalyst and comparsion with MCM-41 material. To test catalytic activity of the new $\mathrm{B}(\mathrm{OEt})_{3}-\mathrm{MCM}-41$ catalyst, MPV reduction reaction of crotonaldehyde was studied.

\section{Experimental}

\subsection{Preparation of mesoporous silica material MCM-41}

Pure siliceous MCM-41 was synthesized following a previously reported procedure. ${ }^{10}$ In a typical synthesis, MCM-41 was prepared by dissolving $19.43 \mathrm{~g}(26.4 \mathrm{mmol})$ of tetraethylammonium hydroxide (TEAOH, 20\%) and $16.16 \mathrm{~g}(12.6 \mathrm{mmol})$ cetyl trimethylammonium chloride (CTMACl, 25\%) in $20 \mathrm{~mL}$ of deionized water with stirring $(1000 \mathrm{rpm})$ until a clear solution was obtained. A measure of $19.27 \mathrm{~g}$ (128.3 mmol) of LUDOX AS-40 (Dupont) was added to the solution with stirring. After $15 \mathrm{~min}$ an additional amount of $32.33 \mathrm{~g}(25.3 \mathrm{mmol})$ CTMACl and $20 \mathrm{~mL} \mathrm{H}_{2} \mathrm{O}$ were added. The resulting mixture was vigorously stirred $(1000 \mathrm{rpm})$ for another $1 \mathrm{~h}$. Molar composition of the final gel mixture was $\mathrm{SiO}_{2}$ : 0.3CTMACl: 0.2TEAOH: $46.3 \mathrm{H}_{2} \mathrm{O}$.

The gel mixture was placed in a Teflon-lined stainless-steel autoclave (BERGHOF BR-200 pressure reactor). The rotating autoclave was heated at $110^{\circ} \mathrm{C}$ for $48 \mathrm{~h}$. The product was washed and calcined as suggested by Uysal and Oksal. ${ }^{4}$

\subsection{Grafting of boron tri-ethoxide}

Boron alkoxide-containing ordered mesoporous silica material was prepared by the grafting method. ${ }^{4,5}$ Prior to grafting, the support (MCM-41) $(2.0 \mathrm{~g})$ was dried at $250^{\circ} \mathrm{C}$ for $2 \mathrm{~h}$. It was then added to a solution of $(1.5 \mathrm{~mL} ; 5.8 \mathrm{mmol}) \mathrm{B}(\mathrm{OEt})_{3}$ (as a $70 \mathrm{wt} \%$ solution in ethanol) in dry hexane $(25 \mathrm{~mL})$. The suspension was stirred $(750 \mathrm{rpm})$ for $4 \mathrm{~h}$ at room temperature. The product was filtered under $\mathrm{N}_{2}$ atmosphere, washed thrice with $10 \mathrm{~mL}$ of hexane and finally dried under the same inert gas flow. The material containing the grafted alkoxide contains $2.6 \mathrm{mmol} \mathrm{B}$ per $\mathrm{g}$ final material and is denoted as $\mathrm{B}(\mathrm{OEt})_{3}$-MCM-41.

\subsection{Characterization}

The surface area, average pore diameter and pore size distribution of MCM-41 support and prepared $\mathrm{B}(\mathrm{OEt})_{3}$ MCM-41 were determined by nitrogen adsorption using a Micromeritics Gemini III 2375 Surface Area Analyser. Prior to measurements, the samples were degassed at $300^{\circ} \mathrm{C}$ and $0.15 \mathrm{mbar}$ at least for $6 \mathrm{~h}$. The surface area was calculated by the method of Brunauer, Emmett and Teller (BET). Pore size distribution curves were obtained from the analysis of desorption branch of the nitrogen adsorption-desorption isotherm by the $\mathrm{BJH}$ (Barrett-Joyner-Halenda) method. The bulk crystalline phases of the samples was determined by powder X-ray diffraction (XRD). This was conducted using a X'Pert Pro MPD Diffractometer from PANalytical, with a $\mathrm{CuK} \alpha 1$ radiation wavelength $0.154 \mathrm{~nm}$.

Thermogravimetric analysis was carried out in nitrogen atmosphere using a high-resolution SII EXSTAR 6000 thermal analyser.

Transmission electron microscopy (TEM) images were recorded on a Tecnai $\mathrm{G}^{2} 20$ S-TWIN with an energy dispersive X-ray spectrometer (EDAX, r-TEM SUTW) located at the ZELMI, TU Berlin.

Boron content of the grafted catalyst was determined by inductively coupled plasma-optical emission spectroscopy (ICP-OES). The mesoporous material $\mathrm{B}(\mathrm{OEt})_{3}$-MCM-41 was dissolved in a mixture solution of $\mathrm{HCl}$ and $\mathrm{HF}$. An aqueous $\mathrm{HCl}$ and $\mathrm{HF}$ solution containing boron was used as standard reference. ICP-OES was performed using Perkin Elmer Optima 4300DV.

The anchoring of boron tri-ethoxide species on MCM-41 was followed by ${ }^{29} \mathrm{Si}$ MAS NMR spectroscopy.

${ }^{29} \mathrm{Si}$ MAS NMR and ${ }^{11} \mathrm{~B}$ MAS NMR spectra were recorded on a Bruker Avance 400 NMR spectrometer with a resonance frequency of 79.46 and $128.3 \mathrm{MHz}$ for ${ }^{29} \mathrm{Si}$ and ${ }^{11} \mathrm{~B}$ using a Bruker $4 \mathrm{~mm}$ double-resonance probe head operating at a spinning rate of $12 \mathrm{kHz}$ for ${ }^{29} \mathrm{Si}$ and ${ }^{11} \mathrm{~B}$. ${ }^{29} \mathrm{Si}$ spectra were collected with $70^{\circ} \mathrm{rf}$ pulses, 30 s delay with $\sim 6000$ scans. ${ }^{11}$ B MAS NMR 


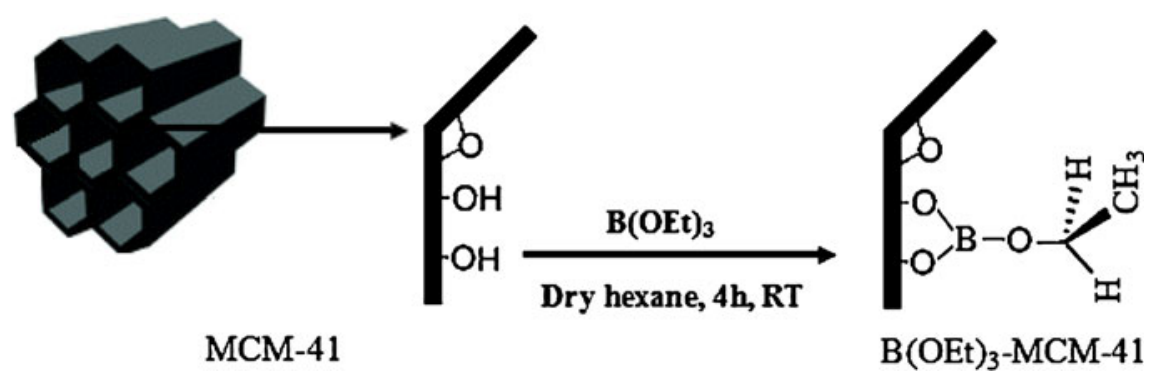

Scheme 1. Schematic representation of MCM-41 and as-synthesized material (B(OEt) $\left.)_{3}-\mathrm{MCM}-41\right)$.

spectra were accumulated for 1024-4096 scans with $\pi / 4$ pulse width of $1.1 \mu \mathrm{s}$ and $2 \mathrm{~s}$ recycle delay.

\subsection{Catalytic activity of $B(O E t)_{3}-M C M-41$}

The $\mathrm{B}(\mathrm{OEt})_{3}-\mathrm{MCM}-41$ catalyst was tested during MPV reduction of crotonaldehyde. The reaction mixture containing $30 \mathrm{mmol}$ of the crotonaldehyde, $200 \mathrm{mmol}$ $(9.214 \mathrm{~g} ; 11.7 \mathrm{~mL})$ ethanol and $500 \mathrm{mg}$ of dried catalyst were placed in a $50 \mathrm{~mL}$ two-mouthed flask with a side stopcock equipped with a $100 \mathrm{~cm}$ condenser. The flask was immersed in an oil bath. The rigorously stirred reaction mixture was gently heated to reflux at $80^{\circ} \mathrm{C}$. During the reduction reaction time, a slow stream of dry nitrogen was passed just over the surface of reaction mixture. By this way, the formed acetaldehyde was removed by nitrogen flow. Thus, the equilibrium shifts more towards product side. Aliquots were removed at different reaction times and analysed by gas chromatography-mass spectrometry (GC-MS).

The reduction products were identified on the basis of their retention times by comparing with authentic samples and their mass spectral fragmentation patterns with those stored in the data bank (Wiley/NIST library). Analyses were performed on a Varian CP 3800 gaschromatograph equipped with a Varian Saturn 2200 MS detector (Walnut Creek, CA, USA) and a VF-5 ms capillary column ( $30 \mathrm{~m}$ length and $0.25 \mathrm{~mm}$ I.D., $0.25 \mu \mathrm{m}$ film thickness) (Palo Alto, CA, USA).

Selectivity towards the but-2-en-1-ol $\left(\mathrm{S}_{\mathrm{UOL}}\right)$ at variable conversion levels was calculated from the following expression: ${ }^{16}$

$$
S_{\mathrm{UOL}}=\left(\frac{\text { mmol of but-2-en-1-ol formed }}{\text { mmol of crotonaldehyde converted }}\right) \times 100 \text {. }
$$

To test for any leaching, about $500 \mathrm{mg}$ of the grafted catalyst was refluxed in $200 \mathrm{mmol}$ of ethanol at $80^{\circ} \mathrm{C}$ for $6 \mathrm{~h}$. The solution was filtered and the filtrate was tested for activity in the MPV reduction of crotonaldehyde. The filtrate and quenched solutions of the catalyst did not show any catalytic activity. This confirms that the activity observed is only due to the solid catalyst and not partly due to the leached active species.

\section{Results and discussion}

Schematic representations of the MCM-41 and assynthesized material $\left(\mathrm{B}(\mathrm{OEt})_{3}-\mathrm{MCM}-41\right)$ are given in scheme 1 . The synthetic procedure adopted for obtaining material $\mathrm{B}(\mathrm{OEt})_{3}-\mathrm{MCM}-41$ catalyst is also given in scheme 1. Similar synthetic procedure and structural formulation for MCM-41 are represented in one of the earlier studies. ${ }^{26}$ Removal of the template (CTMACl) from as-synthesized MCM-41 may open mesopores as well as easily cause structure shrinkage. ${ }^{27}$ Most of the

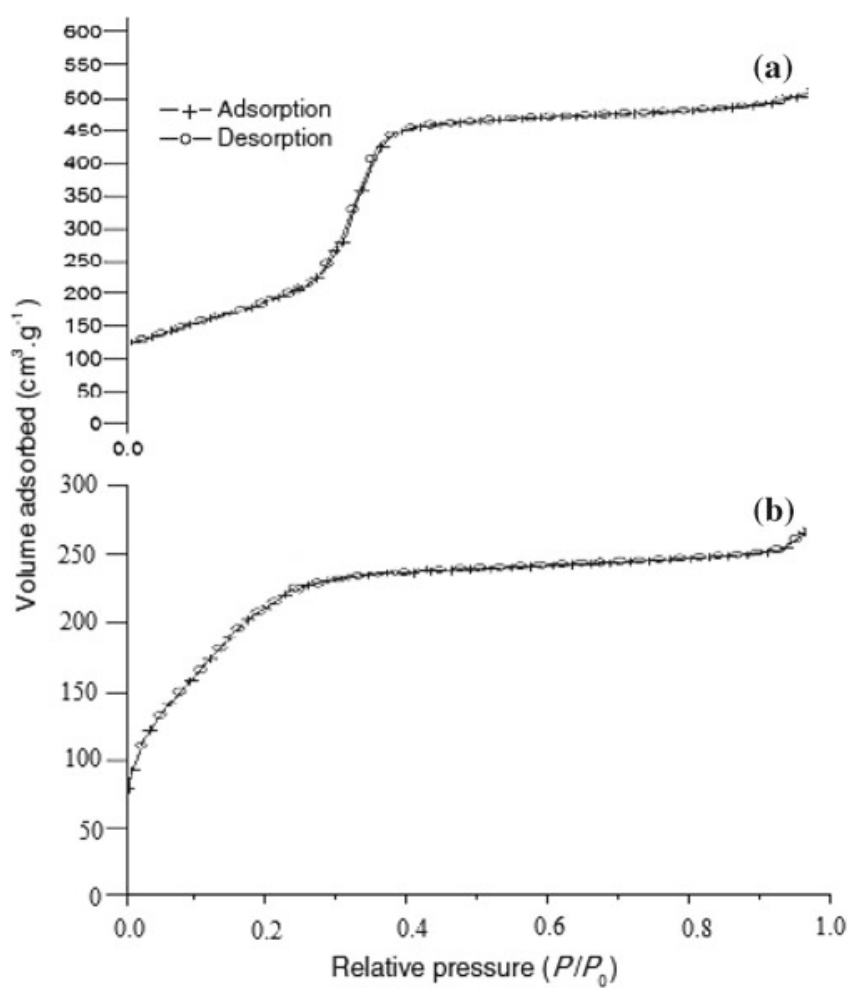

Figure 1. $\mathrm{N}_{2}$ adsorption/desorption isotherms of (a) MCM-41 and (b) B(OEt) 3 -MCM-41. 
Table 1. Surface properties of MCM-41 and B(OEt) $)_{3}-\mathrm{MCM}-41$.

\begin{tabular}{lccc}
\hline Sample & $\begin{array}{c}\text { BET surface } \\
\text { area }\left(\mathrm{m}^{2} / \mathrm{g}\right)\end{array}$ & $\begin{array}{c}\text { Pore volume } \\
\left(\mathrm{cm}^{3} / \mathrm{g}\right)\end{array}$ & $\begin{array}{c}\text { Pore diameter } \\
(\AA)\end{array}$ \\
\hline MCM-41 & 1100 & 0.38 & 25.1 \\
$\mathrm{~B}(\mathrm{OEt})_{3}$-MCM-41 & 762 & 0.12 & 20.8 \\
\hline
\end{tabular}

high molecular weight surfactant is removed from assynthesized MCM-41 via calcination. So, the preparation of MCM-41 materials usually includes a high temperature calcination for destroying the surfactant template.

\subsection{Characterization of materials}

The as-obtained MCM-41 and $\mathrm{B}(\mathrm{OEt})_{3}$-MCM-41 samples were investigated with various analytical methods including $\mathrm{N}_{2}$ adsorption/desorption measurements (Brunauer-Emmett-Teller method), high-resolution thermogravimetry (TGA), XRD and TEM techniques, ${ }^{29}$ Si MAS NMR and ${ }^{11} \mathrm{~B}$ MAS NMR spectroscopies.

The $\mathrm{N}_{2}$ adsorption-desorption isotherms for the MCM-41 and $\mathrm{B}(\mathrm{OEt})_{3}-\mathrm{MCM}-41$ samples are shown in figure 1 . The $\mathrm{N}_{2}$ isotherm for the MCM-41 sample is shown in figure 1 (a). It is a typical type IV adsorption isotherm as defined by IUPAC nomenclature without any hysteresis, and shows a sharp capillary condensation step at a relative pressure between 0.2 and 0.4. ${ }^{28-31}$ A sharp inflection between relative pressure $P / P_{0}=0.2$ and 0.4 corresponds to capillary condensation within uniform mesopores. The sharpness of this step reflects the uniform pore size. ${ }^{32}$ Compared to the untreated MCM-41 sample, the sharp capillary condensation step in the case of incorporated MCM41 samples shifts toward lower $P / P_{0}$ region. This suggests that the introduction of $\mathrm{B}(\mathrm{OEt})_{3}$ into the channel causes changes in the pore structure of the support during the incorporation process. Also, $\mathrm{B}(\mathrm{OEt})_{3}-\mathrm{MCM}-41$ still displays a type IV adsorption isotherm according to IUPAC without any hysteresis between the adsorption and the desorption curves (figure 1 (b)).

As seen in table 1 before functionalization with $\mathrm{B}(\mathrm{OEt})_{3}$, the calcined MCM-41 has a surface area of $1100 \mathrm{~m}^{2} / \mathrm{g}$, with an average pore diameter of $25.1 \AA$ as deduced using the Barrett-Joyner-Halenda method. Specific surface decreases to $762 \mathrm{~m}^{2} / \mathrm{g}$, with an average pore diameter of $20.8 \AA$. This implies that the surface functionalization to some extent decreases the available pore volume and diameter, but the material still has all the characteristics of an ordered, mesoporous support.

The low-angle XRD patterns of MCM-41 and $\mathrm{B}(\mathrm{OEt})_{3}-\mathrm{MCM}-41$ are shown in figure 2 (a) and (b), respectively. X-ray diffractograms of the MCM-41 and $\mathrm{B}(\mathrm{OEt})_{3}-\mathrm{MCM}-41$ materials were characterized by three distinct Bragg reflexes at low angles indexed to (100), (110) and (200) representatives of ordered

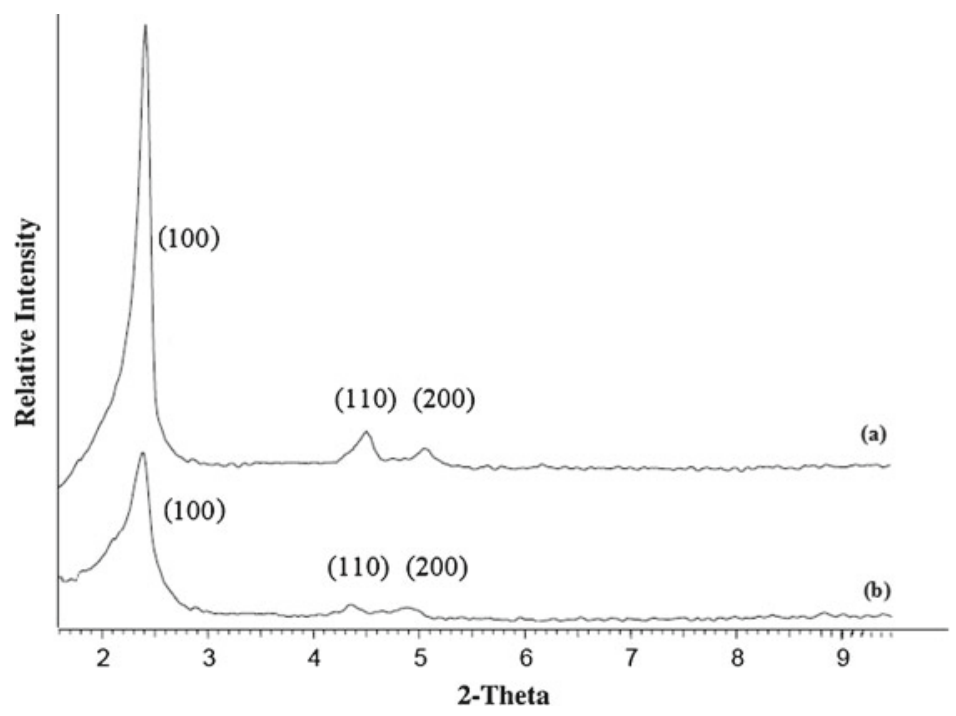

Figure 2. Low-angle XRD patterns of (a) unmodified and (b) $\mathrm{B}(\mathrm{OEt})_{3}$ modified MCM-41 supports. 


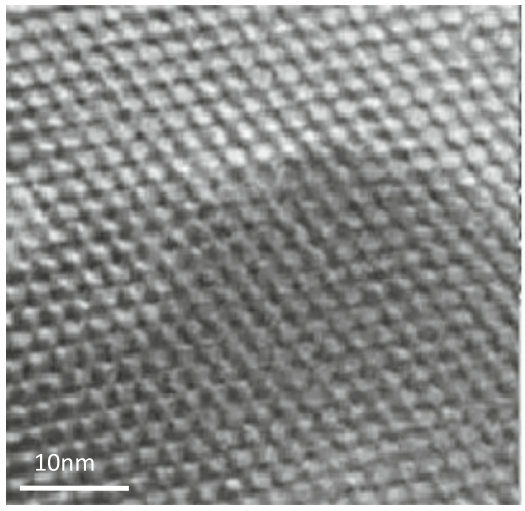

(a)

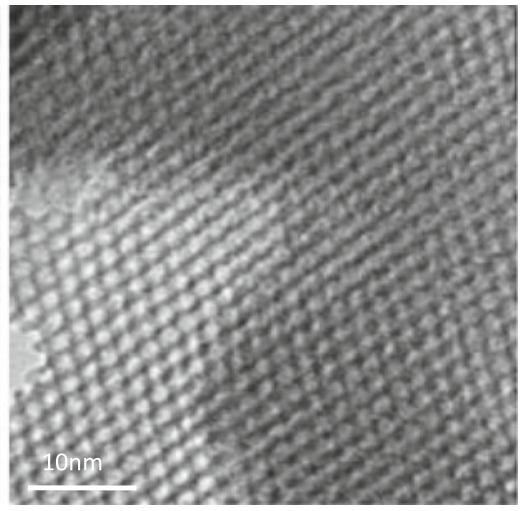

(b)

Figure 3. TEM of (a) MCM-41 and (b) $\mathrm{B}(\mathrm{OEt})_{3}-\mathrm{MCM}-41$.

materials with hexagonal arrangement of mesopores (figure 2 (a) and (b)). The XRD pattern of the untreated MCM-41 exhibits a high intensity (100) and two low intensity reflections (110) and (200), which are characteristic of the hexagonal mesoporous MCM-41. ${ }^{33}$ After the incorporation of boron alkoxide complex into the framework, the main peak intensity decreases. This result indicates that the incorporation of boron alkoxide complexes in the channel of MCM-41 leads to a substantial loss in the scattering contrast between the channel and the wall, and reduces the intensity of the scattered X-ray in the powder diffraction experiment. ${ }^{34}$ Furthermore, intensity of the two less intense reflections (110) and (200) decreases much more. This observation is supported by a drop in the pore volume and the surface area (table 1).

ICP-OES analysis showed $2.81 \mathrm{wt} \%$ of boron content in the catalyst. To determine boron content, $\mathrm{B}(\mathrm{OEt})_{3}$ MCM-41 was dissolved in a mixture solution of $\mathrm{HCl}$ and $\mathrm{HF}$. An aqueous $\mathrm{HCl}$ and $\mathrm{HF}$ solution containing boron was used as standard reference; $2.6 \mathrm{mmol} \mathrm{B}$ was found per $\mathrm{g}$ of $\mathrm{B}(\mathrm{OEt})_{3}-\mathrm{MCM}-41$.

Figure 3 shows the representative TEM images of $\mathrm{MCM}-41$ and $\mathrm{B}(\mathrm{OEt})_{3}-\mathrm{MCM}-41$. The highly ordered

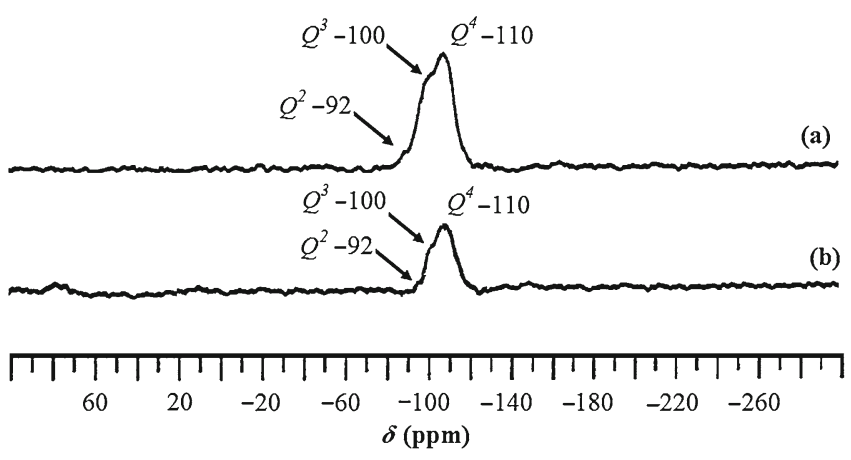

Figure 4. ${ }^{29} \mathrm{Si}$ solid-state MAS NMR spectra of (a) pure MCM-41 and (b) B(OEt) 3 -MCM-41. hexagonal arrays of mesoporous channels confirm the existence of a hexagonal mesostructure for $\mathrm{B}(\mathrm{OEt})_{3^{-}}$ MCM-41. These images reveal that the hexagonally ordered mesostructure of the MCM-41 host material was unaffected by grafting of boron tri-ethoxide.

Grafting of $\mathrm{B}(\mathrm{OEt})_{3}$ on the calcined MCM-41 material was followed by ${ }^{29} \mathrm{Si}$ solid state NMR. ${ }^{29} \mathrm{Si}$ MAS NMR spectra of calcined mesoporous MCM-41 and $\mathrm{B}(\mathrm{OEt})_{3}$-MCM-41 samples are shown in figure 4 . Presence of broad resonance peaks from -90 to $-110 \mathrm{ppm}$, indicative for a range of $\mathrm{Si}-\mathrm{O}-\mathrm{Si}$ bond angles and the formation of more tetrahedral silicon environments. The ${ }^{29} \mathrm{Si}$ MAS NMR spectrum of the calcined MCM-41 shows signals of $Q^{4}$ species ( $\mathrm{Si}(4 \mathrm{OSi})$ ) at $-110 \mathrm{ppm}, Q^{3}$ species $(\mathrm{Si}(3 \mathrm{OSi}, 1 \mathrm{OH}))$ at $-100 \mathrm{ppm}$, and $Q^{2}$ species $(\mathrm{Si}(2 \mathrm{OSi}, 2 \mathrm{OH}))$ at $-92 \mathrm{ppm}$. Compared to MCM-41, the spectrum of $\mathrm{B}(\mathrm{OEt})_{3}-\mathrm{MCM}-41$ shows a marked decrease in the intensity of the $Q^{3}$ and $Q^{2}$ signals, due to the substitution of hydroxyl groups belonging to $Q^{2}$ or $Q^{3}$ with boron alkoxide-complex during the incorporation process. In addition, the ${ }^{11} \mathrm{~B}$ NMR of the $\mathrm{B}(\mathrm{OEt})_{3}-\mathrm{MCM}-41$ reveals the presence of 3-fold coordinated boron with a very characteristic peak around $21 \mathrm{ppm}$ as shown in figure 5 indicating the successful modification of MCM- 41 by boron ethoxide.

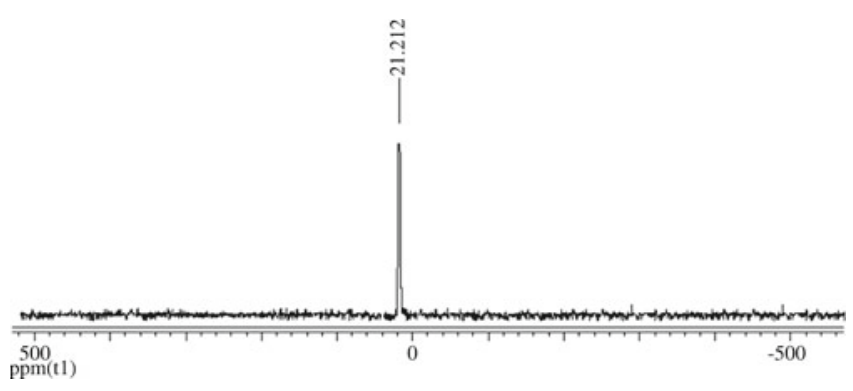

Figure 5. ${ }^{11} \mathrm{~B}$ NMR spectra of $\mathrm{B}(\mathrm{OEt})_{3}-\mathrm{MCM}-41$. 


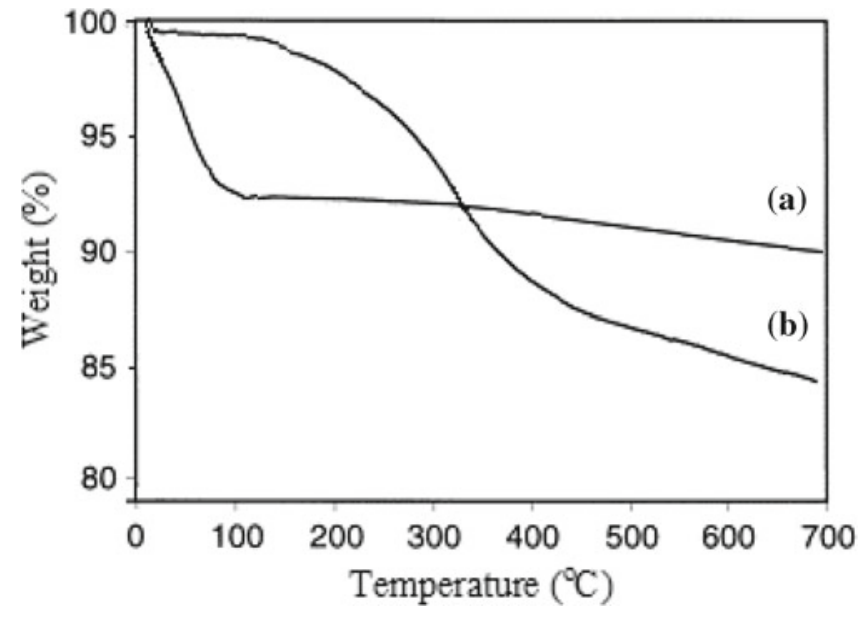

Figure 6. Weight loss curves for (a) unmodified MCM-41 and (b) $\mathrm{B}(\mathrm{OEt})_{3}-\mathrm{MCM}-41$.

Thermogravimetric weight loss curves for MCM41 and $\mathrm{B}(\mathrm{OEt})_{3}-\mathrm{MCM}-41$ are shown in figure 6 . It can be seen that unmodified MCM-41 exhibited a major weight loss at temperatures up to ca. $100^{\circ} \mathrm{C}$, which can be attributed to the release of physically adsorbed water ${ }^{35,36}$ and therefore indicates a relatively hydrophilic character of its surface. At higher temperatures, the TGA curve was very flat, especially up to ca. $600^{\circ} \mathrm{C}$, showing that there is no remarkable condensation of silanol groups on the surface of the material. $^{35,36}$ Weight loss profile of the MCM-41 material was significantly altered as a result of the modification. In the case of samples with boron alkoxides bonded ligands (see figure 1), weight loss up to $100^{\circ} \mathrm{C}$ was very small. At higher temperatures, the TGA curves were initially flat and then exhibited a rapid decline in the temperature range from ca. 383 to $600 \mathrm{~K}$, followed by a more gradual weight loss. Prominent steps on the TGA curves can be attributed to the decomposition of bonded boron alkoxide moieties, and their height is roughly proportional to carbon contents in the samples.

\subsection{Activity of $B(O E t)_{3}-M C M-41$ material}

The MPV reaction have been catalysed by various metal alkoxides such as aluminum 2-propoxide, zirconium 1-propoxide, etc. ${ }^{37}$ Also, different boron alkoxides such as boron 2- propoxide, boron tri-ethoxide, etc., have been used in the MPV reductions. ${ }^{38,39}$ In this study, we first aimed to prepare the new material MCM41 functionalized with boron tri-ethoxide and compare the surface properties with pure MCM-41. Second, we wanted to show the applicability of the new material as heterogenous catalyst in the MPV reduction.

High surface area mesoporous material such MCM41 provides useful support for the heterogenization of boron alkoxides. ${ }^{4,10}$ Surface hydroxyl groups are involved in the grafting reaction, probably allowing boron tri-ethoxide to build up to a monolayer. Therefore, MCM-41 with hexagonal pore structure will favour easy access of the reactants to the B centres. And thus, MCM-41 will increase the reaction rate. ${ }^{4}$ This is consistent with the tendency of B-alkoxides to form aggregates in homogeneous reaction medium. So, compared with homogeneous catalysts, heterogeneous boron alkoxide catalysts which are dispersed over the siliceous surface by reaction with the surface silanol groups, have more available B centres for MPV reaction. ${ }^{40}$

Herein, we reported that our preliminary results on the development of $\mathrm{B}(\mathrm{OEt})_{3}-\mathrm{MCM}-41$ catalyst can be employed for the chemoselective catalytic MPV reduction of various aldehydes and ketones under mild reaction conditions. For this purpose, $\mathrm{B}(\mathrm{OEt})_{3}-\mathrm{MCM}-41$ was tested for chemoselective reduction of crotonaldehyde to but-2-en-1-ol (scheme 2).

Reaction mechanism for the homogeneous MPV reaction involves a cyclic six-membered transition state. ${ }^{41-43}$ Recent studies by Creyghton et al. ${ }^{13}$ proposed that over heterogeneous catalysts such as zeolite beta, the MPV mechanism also involves a six-membered transition state, where both the alcohol and the ketone coordinate to the same Lewis acid site. ${ }^{40}$ In this regard, the reaction mechanism for the reduction reaction of crotonaldehyde can be presumed to be similar to the classical MPV reduction of carbonyls reported for aluminium isopropoxide and boron tri-isopropoxide. ${ }^{4,8,39}$ Scheme 3 shows the proposed mechanism for the MPV reduction of crotonaldehyde in the presence of $\mathrm{B}(\mathrm{OEt})_{3}$ MCM-41. First, the carbonyl compound is coordinated to the boron of the boron alkoxide. The reaction proceeds by hydride-transfer to the carbonyl compound

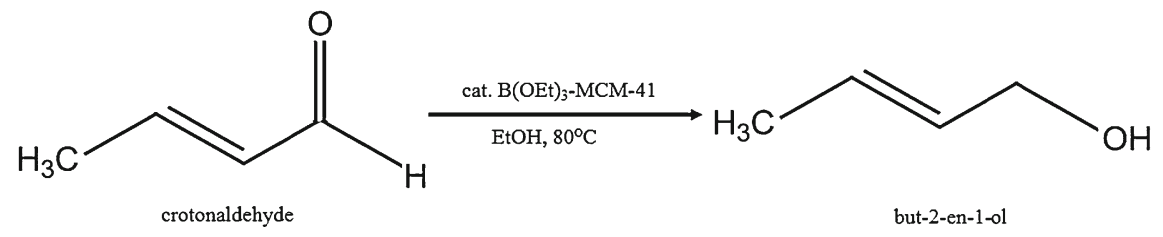

Scheme 2. MPV reduction of crotonaldehyde using $\mathrm{B}(\mathrm{OEt})_{3}-\mathrm{MCM}-41$ catalyst. 


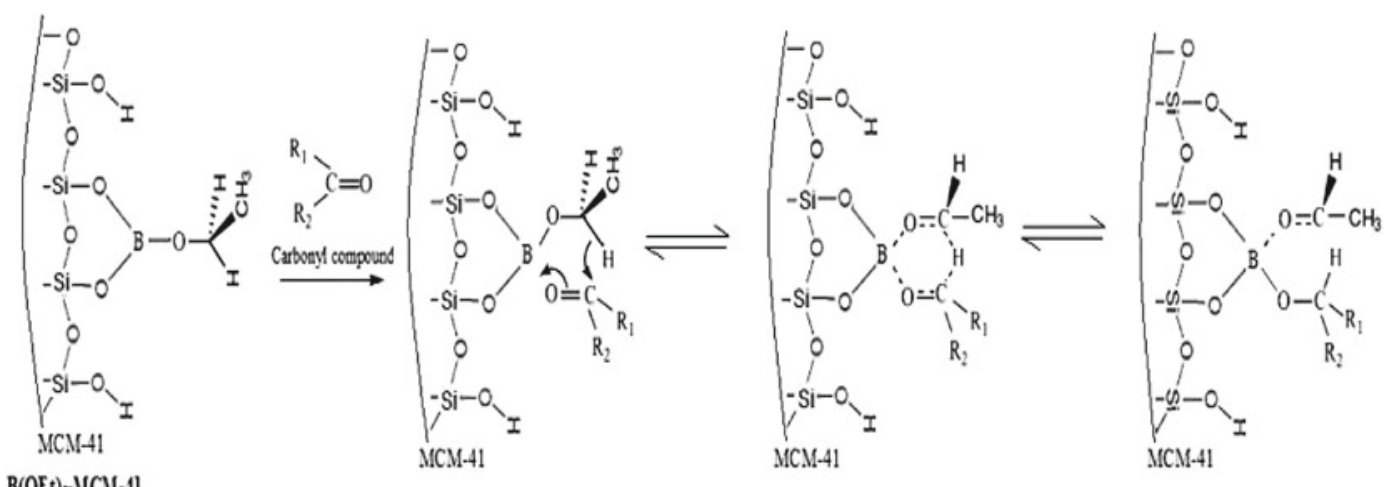

$\left.\mathrm{B}(\mathrm{OEt})_{r} \mathrm{MICI}-4\right]$

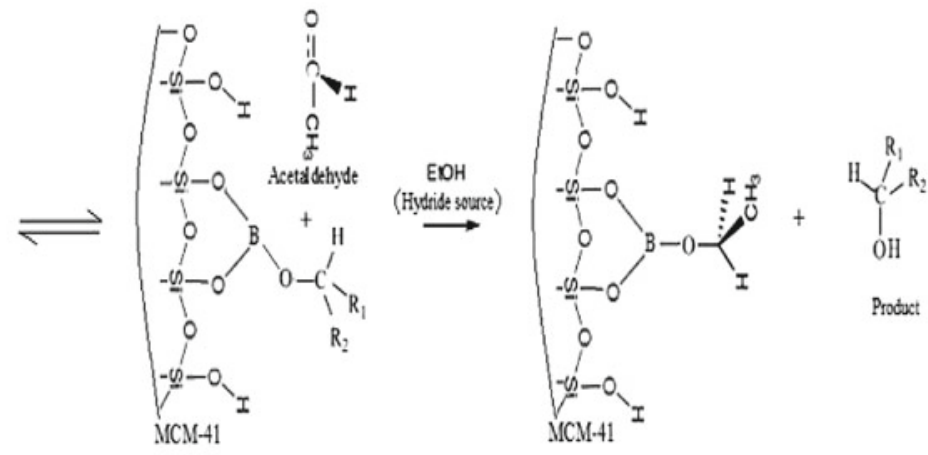

\section{$\mathrm{R}_{1}=\mathrm{H} \mathrm{R}=\mathrm{CH} 3 \mathrm{CHCH}-$}

Scheme 3. Proposed mechanism for the MPV reduction of crotonaldehyde in the presence of $\mathrm{B}(\mathrm{OEt})_{3}-\mathrm{MCM}-41$.

from the alcohol, which is bound to the boron centre as an alkoxide. Since the reduction is reversible, the acetaldehyde was removed from the medium by a slow stream of nitrogen. Removal of acetaldehyde from the reaction solution leads to the progress of the reaction to the right hand side. ${ }^{42} \mathrm{~B}\left(\mathrm{O}^{i} \mathrm{Pr}\right)_{3}-\mathrm{MCM}-41$ also reduces carbonyl compounds with a similarmechanism; the acetone produced was removed by the same procedure. ${ }^{4}$ Removal of acetone (bp $81^{\circ} \mathrm{C}$ ) is more difficult than acetaldehyde (bp $56^{\circ} \mathrm{C}$ ). Therefore, the yield of the alcohol products from reduction will be greater thanthose using $\mathrm{B}\left(\mathrm{O}^{i} \mathrm{Pr}\right)_{3}-\mathrm{MCM}-41$.

It is found that $\mathrm{B}(\mathrm{OEt})_{3}-\mathrm{MCM}-41$ is an active catalyst in the MPV reduction of crotonaldehyde. Yield of the reduction product, reaction time and chemoselectivity to but-2-en-1-ol in the presence of heterogeneous catalyst were summarized in table 2 . As seen in table 2 , in the presence of $\mathrm{B}(\mathrm{OEt})_{3}-\mathrm{MCM}-41$, the desired but-2-en-1-ol was obtained with high selectivity at high crotonaldehyde conversion (table 2). The important carbonyl compound possesses conjugated $\mathrm{C}=\mathrm{C}$ and $\mathrm{C}=\mathrm{O}$ bonds. The $\mathrm{C}=\mathrm{C}$ bonds are more readily hydrogenated than the $\mathrm{C}=\mathrm{O}$ bonds in most usual techniques. ${ }^{44}$ Although reduction of the $\mathrm{C}=\mathrm{O}$ bonds without affecting the $\mathrm{C}=\mathrm{C}$ bonds is very difficult, $\mathrm{C}=\mathrm{O}$ bond of this compound was reduced using $\mathrm{B}(\mathrm{OEt})_{3^{-}}$ MCM-41 catalyst. An interesting result was that the selectivity towards the reduced product was $99 \%$ in the

Table 2. Reduction of crotonaldehyde to but-2-en-1-ol under different reaction conditions: reduction time, product alcohol yields, chemoselectivity to but-2-en-1-ol: comparison with $\mathrm{Zr}$ (100) catalyst.

\begin{tabular}{|c|c|c|c|c|c|c|c|}
\hline System & Yield (\%) & Selectivity (\%) & $\mathrm{t}(\mathrm{h})$ & System (ref. 45) & Yield $(\%)$ & $\mathrm{t}(\mathrm{h})$ & Selectivity (\%) \\
\hline $\mathrm{B}(\mathrm{OEt})_{3}-\mathrm{MCM}-41$ & $89.8^{[\mathrm{a}]}$ & 99 & 5 & $\mathrm{Zr}(100)$ & $95.2^{[\mathrm{a}]}$ & 6 & 100 \\
\hline No catalyst & $-[b]$ & & & & & & \\
\hline Filtrate & $-[b]$ & & & & & & \\
\hline Quenched solution & _[b] & & & & & & \\
\hline $\mathrm{B}(\mathrm{OEt})_{3}$ free $\mathrm{MCM}-41$ & $-[b]$ & & & & & & \\
\hline
\end{tabular}

Reaction condition: Crotonaldehyde $(30 \mathrm{mmol})$, catalyst $(500 \mathrm{mg})$ in ethanol $(200 \mathrm{mmol}, 15.4 \mathrm{~mL})$ refluxed at $353 \mathrm{~K}$ for $6 \mathrm{~h}$ ${ }^{[a]}$ Yield on single experiment

${ }^{[b]}$ No reaction 
presence of heterogeneous catalyst, showing that the supported boron alkoxide catalyst is highly selective.

To show catalytic efficiency of $\mathrm{B}(\mathrm{OEt})_{3}-\mathrm{MCM}-41$ catalyst according to different MPV catalysts, heterogeneous boron tri-ethoxide catalyst compared with $\mathrm{Zr}$ (100) $(\mathrm{Si} / \mathrm{Zr}$ ratio of 100$) \mathrm{MPV}$ catalyst in table $2 .{ }^{45}$ In the literature, it was found that $\mathrm{Zr}$-zeolite beta is a very efficient catalyst for the reduction of alkyl- and aryl-saturated ketones. ${ }^{46}$ Lewis acid sites resulting from the incorporation of $\mathrm{Zr}$ into the zeolite framework were considered as active centres of the zeolite. $\mathrm{Zhu}$ and coworkers investigated the use of $\mathrm{Zr}$-zeolite beta in the MPV reduction of $\alpha, \beta$-unsaturated aldehydes. ${ }^{45}$ In comparison with heterogeneous $\operatorname{Zr}(100)$ catalyst, for crotonaldehyde, the $\mathrm{B}(\mathrm{OEt})_{3}-\mathrm{MCM}-41$ heterogeneous catalyst shows similar activity (yield) and selectivity. ${ }^{46}$ As shown in table 2, but-2-en-1-ol yield is $95.2 \%$ for $\mathrm{Zr}(100)$ and $89.8 \%$ for $\mathrm{B}(\mathrm{OEt})_{3}-\mathrm{MCM}$ 41 catalyts. Also, comparing $\mathrm{B}(\mathrm{OEt})_{3}-\mathrm{MCM}-41$ catalyst with $\mathrm{Zr}$ (100) catalyst, it was found that in the presence of $\mathrm{B}(\mathrm{OEt})_{3}-\mathrm{MCM}-41$ catalyst, crotonaldehyde was reduced with reduced reaction time (table 2). Therefore, $\mathrm{B}(\mathrm{OEt})_{3}$-MCM-41 catalyst is as good as $\mathrm{Zr}(100)$ catalyst with respect to MPV reduction of crotonaldehyde. ${ }^{45}$

\section{Conclusion}

Modification with boron-tri-ethoxide groups of MCM41 material creates new Lewis acid sites (of moderate and stronger Lewis acidity, according to the $\mathrm{B}\left(\mathrm{O}^{i} \mathrm{Pr}\right)_{3}$ MCM-41 results) while, to a certain degree, the initial structural characteristics (high surface area, narrow pore size distribution, and crystalline hexagonal structure) are preserved.

In conclusion, we have devised an essentially new boron alkoxide based heterogeneous ' $\mathrm{B}(\mathrm{OEt})_{3}$-MCM41 ' catalyst. The $\mathrm{B}(\mathrm{OEt})_{3}-\mathrm{MCM}-41$ catalyst was tested in MPV reduction of crotonaldehyde. The catalyst prepared in this study possess sufficient catalytic activity in the MPV reduction of crotonaldehyde. It is useful for high catalytic activity with $\mathrm{EtOH}$ as a hydride donor in the MPV reduction of various $\alpha, \beta$-unsaturated carbonyl groups. It has a remarkable potential for practical use since heterogeneous $\mathrm{B}(\mathrm{OEt})_{3}-\mathrm{MCM}-41$ catalyst offers the advantage of ease of separation.

\section{Acknowledgement}

The authors thank Scientific Research Projects Unit of Akdeniz University for financial support.

\section{References}

1. Kresge C T, Leonowicz M E, Roth W J, Vartuli J C and Beck J S 1992 Nature 359710

2. Yue Y, Gedeon A, Bonardet J L, Melosh N, d'Espinose J B and Fraissard J 1999 Chem. Commun. 191967

3. Berlini C, Guidotti M, Moretti G, Psaro R and Ravasio N 2000 Catal. Today 60219

4. Uysal B and Oksal B S 2012 Appl. Catal. A-Gen 435204

5. De bruyn M, De Vos D E and Jacobs P A $2002 A d v$. Synth. Catal. 3441120

6. Quignard F, Graziani O and Choplin A 1999 Appl. Catal. A 18229

7. Leyrit P, Mc Gill C, Quignard F and Choplin A 1996 J. Mol. Catal. A: Chem. 112395

8. Anwander R, Palm C, Gerstberger G, Groeger O and Engelhardt G 1998 Chem. Commun. 1811

9. Inada K, Shibagaki M, Nakanishi Y and Matsushita H 1993 Chem Lett. 221795

10. Uysal B, Aksu Y and Oksal B S 2013 J. Porous Mat. 20 115

11. Minambres J F, Aramendia M A, Marinas A, Marinas J M and Urbano F J 2011 J. Mol. Catal. A: Chem. 338 121

12. Urbano F J, Aramendía M A, Marinas A and Marinas J M 2009 J. Catal. 26879

13. Creyghton E J, Ganeshie S D, Downing R S and van Bekkum H 1997 J. Mol. Catal. A 115457

14. Creyghton E J and Downing R S 1998 J. Mol. Catal. A: Chem 13447

15. Creyghton E J, Huskens J, van der Waal J C and van Bekkum H 1997 In Heterogeneous catalysis and fine chemicals IV (eds) H U Blaser, A Baiker and R Prins (Amsterdam: Elsevier) p. 531

16. Kunkeler P J, Zuurdeeg B J, van der Waal J C, van Bokhoven J A, Koningsberger D C and van Bekkum H 1998 J. Catal. 180234

17. Corma A, Domine M E and Valencia S 2003 J. Catal. 215294

18. Anwander R and Palm C 1999 Stud. Surf. Sci. 117 413

19. Ivanov V A, Bachelier J, Audry F and Lavalley J C 1994 J. Mol. Catal. 9145

20. Sayari A, Danumah C and Moudrakovski I L 1995 Chem. Mater. 7813

21. On T D, Joshi P N and Kaliaguine S 1996 J. Phys. Chem. 1006743

22. Charoenchaidet S, Chavadej S and Gulari E 2002 J. Mol. Catal. A-Chem. 185167

23. Jiamwijitkul S, Jongsomjit B and Praserthdam P 2007 Iran. Polym. J. 16549

24. Conesa T D, Campelo J M, Luna D, Marinas J M and Romero A A 2007 Appl. Catal. B: Environ. 70567

25. Grün M, Unger K, Matsumoto A and Tsutsumi K 1999 Micropor. Mesopor. Mater. 27207

26. Maity N, Rajamohanan P R, Ganapathy S, Gopinath C S, Bhaduri S and Lahiri G K 2008 J. Phys. Chem. C 112 9428

27. Chen C Y, Li H X and Davis M E 1993 Microporous Mater. 217

28. Vetrive S and Pandurangan A 2005 Catal. Lett. 99 3-43-141 
29. Ziolek M, Lewandowska A and Grybowska B 2003 React. Kinet. Catal. Lett. 802

30. Gao X, Wachs I E, Wong M S and Ying J Y $2001 \mathrm{~J}$. Catal. 20318

31. Mathew T, Sivaranjani K, Gnanakumar E S, Yamada Y, Kobayashia T and Gopinath C S 2012 J. Mater. Chem. 2213484

32. Xu J, Luan Z, He H, Zhou W and Kevan L 1998 Chem. Mater. 103690

33. Park S E, Kim D S, Chang J S and Kim W Y 1998 Catal. Today. 44301

34. Kinski I, Gies H and Marlow F 1997 Zeolite 19375

35. Jaroniec C P, Gilpin R K and Jaroniec M 1997 J. Phys. Chem. B. 1016861

36. Iler R K 1979 The chemistry of silica (Wiley: New York)
37. Namy J L, Souppe J and Collin Kagan J H B 1984 J. Org. Chem. 492045

38. Uysal B and Buyuktas B S 2007 Arkivoc 14134

39. Uysal B and Oksal B S 2011 J. Chem. Sci. 123681

40. Bruyn M D, Limbourg M, Denayer J, Baron G V, Parvulescu V, Grobet P J, De Vos D E and Jacobs P A 2003 Appl. Catal. A. 254189

41. De Graauw C F, Peters J A, van Bekkum H and Huskens J 1994 Synthesis. 101007

42. Uysal B and Buyuktas B S 2012 Chem. Pap. 64123

43. Zhu Y, Liu S, Jaenicke S and Chuah G 2004 Catal. Today 97249

44. Narayanan S 2003 Bull. Catal. Soc. India 2107

45. Zhu Y, Chuah G K and Jaenicke S 2006 J. Catal. 24125

46. Zhu Y Z, Chuah G K and Jaenicke S 2004 J. Catal. 2271 